\title{
Online Therapy for Depressive Symptoms: An Evaluation of Counselor-Led and Peer-Supported Life ReviewTherapy
}

\author{
Gerben J. Westerhof, PhD,* Sanne M. A. Lamers, PhD, Marloes G. Postel, PhD, and \\ Ernst T. Bohlmeijer, PhD
}

Department of Psychology, Health and Technology, Center for eHealth and Well-Being Research, University of Twente, Enschede, the Netherlands.

*Address correspondence to: Gerben J. Westerhof, PhD, Department of Psychology, Health and Technology, Center for eHealth and Well-Being Research, University of Twente, PO Box 217, 7500AE Enschede, the Netherlands. E-mail: g.j.westerhof@utwente.nl

Received: April 7, 2017; Editorial Decision Date: July 30, 2017

Decision Editor: Suzanne Meeks, PhD

\begin{abstract}
Objectives: Life review therapy is recognized as an evidence-based treatment for depression in later life. The current article evaluates an online life review therapy in middle-aged and older persons, comparing a counselor-led to a peer-supported mode of delivery.

Methods: A pilot randomized controlled trial (RCT) was carried out with 3 conditions and 4 measurement points: (a) online life review therapy with online counseling, (b) online life review therapy with online peer support, and (c) a waitlist control condition. A mixed methods study provided insight in the reach, adherence, effectiveness, user experiences, and acceptability.

Results: Fifty-eight people were included in the study. The intervention reached a vulnerable group of mainly middle-aged, college-educated women. The pilot RCT on effectiveness showed that participants in all conditions improved significantly in depressive symptoms, engaged living, mastery, and vitality, but not in ego integrity and despair, social support, loneliness, and well-being. The adherence, user experience, and acceptability were better in the counselor condition than in the peer condition. No differences were found between middle-aged and older adults.

Conclusion: Despite the nonsignificant effects, possibly due to the small sample size, online life review therapy might be a good method for alleviating depressive symptoms in people in their second half of life. Further research is needed, addressing how online life review is best offered.
\end{abstract}

Keywords: Depression, Life review, Mental health (services, therapy), Technology

A long tradition of research has shown that how people reminisce about their lives is related to their well-being and mental health (Westerhof, Bohlmeijer, \& Webster, 2010). Recollecting vivid positive memories, evaluating negative memories, and integrating memories across different phases of the lifespan are of particular importance (Westerhof \& Bohlmeijer, 2014). Life review therapy combines these insights with psychotherapeutic methods in order to change negative reminiscence styles and support mental health and well-being (Westerhof et al., 2010).
Life review therapy is recognized as an evidence-based treatment for depression in later life with similar effect sizes as cognitive behavioral therapy (Bohlmeijer, Smit, \& Cuijpers, 2003; Pinquart \& Forstmeier, 2012; Scogin, Welsh, Hanson, Stump, \& Coates, 2005). The current article evaluates an innovative, internet-based way of delivering life review therapy for depressive symptoms. We were especially interested in the possibilities of a counselor-led versus a peer-supported mode of delivery to both middleaged and older persons. 
In everyday life, digital technologies play an increasingly important role in reminiscence and life review where they serve as a kind of external autobiographical memory (Westerhof, 2017). Social media, like Facebook, Instagram, or Youtube, allow storing and sharing memories as well as triggering and stimulating processes of reminiscence and life review (Thomas \& Briggs, 2016). Digital technologies are increasingly used to promote reminiscence and life review in interventions, for example, in online life story books (Lazar, Thompson, \& Demiris, 2014). However, an evaluation of a completely online life review therapy is still lacking.

Meta-analyses have shown that internet-based therapies, like cognitive behavioral therapy, are effective in treating depressive symptoms (Sander, Rausch, \& Baumeister, 2016). Internet therapies are attractive to those who are open to communicate their thoughts and emotions in a virtual relationship (Beattie, Shaw, Kaur, \& Kessler, 2009). They can be followed in one's own place and time and are often perceived as flexible, anonymous, and nonstigmatizing (Cuijpers, van Straten, Warmerdam, \& Van Rooy, 2010). Furthermore, they are attractive to health care organizations as they fit the shifting focus toward more self-management in care (Van Gemert-Pijnen, Peters, \& Ossebaard, 2013) and can be cost-effective (Buntrock et al., 2017).

An important question is what mode of delivery of internet-based interventions would be best for online life review therapy. There has been some debate on the role of counselors versus peers in life review therapy (Korte, Drossaert, Westerhof, \& Bohlmeijer, 2014). Individual therapy provides the best opportunities to adapt to personal needs and sensitive issues (Haight, Coleman, \& Lord, 1995) whereas group therapy allows for social exchange and learning from peers (Birren \& Deutchman, 1991).

Previous studies on internet-based interventions have mainly compared counselor-led to unguided interventions and found that the previous are more effective (Griffiths, Farrer, \& Christensen, 2010). Some studies showed that peer supported internet-based interventions contribute to empowerment of clients (Melling \& Houguet-Pincham, 2011) and reduction of depressive symptoms (Griffiths et al., 2012). However, studies that directly compare the effects of counselor-led and peer-supported interventions are lacking.

A second important question concerns the target age group of internet-based life review therapy. Older adults are among the fastest growing group of internet users. For example, 8 out of 10 Dutch persons between 65 and 75 years have used the internet on a weekly basis in 2013, a figure doubled since 2005 (CBS, 2015). However, their internet skills still tend to lag behind those of younger generations (Van Deurzen \& Van Dijk, 2015). It is therefore important to evaluate an online format across different age groups.

Over the past decades, life review therapy has been developed especially for older adults (Westerhof et al.,
2010). However, people tend to think back and reflect on their lives throughout the lifespan and not only in later life (Fivush et al., 2011). It is nowadays acknowledged that reminiscence serves a variety of integrative, instrumental, and social functions besides death acceptance in the latest phase of life (Westerhof \& Bohlmeijer, 2014). Hence, life review therapy might be effective in other age groups as well (Hallford \& Mellor, 2016; Lamers, Bohlmeijer, Korte, \& Westerhof, 2015).

We carried out an evaluation of online life review therapy, comparing counselor-led and peer-supported delivery among middle-aged and older adults. The evaluation was guided by five participant-related issues that play a role in the use and effectiveness of internet interventions: reach, adherence, effectiveness, user experience, and acceptability (Berry, Lobban, Emsley, \& Bucci, 2016; Feather et al., 2016; Kelders, Kok, Ossebaard, \& Van Gemert-Pijnen, 2012; Kohl, Crutzen, \& de Vries, 2013).

Internet interventions tend to reach a limited group of often middle-aged, higher educated women (Kelders, Bohlmeijer, \& Van Gemert-Pijnen, 2013). It is therefore important to know more about the reach of the intervention: we compare participant characteristics to the general population as well as to a face-to-face group format of life review therapy (Korte, Bohlmeijer, Cappeliez, Smit, \& Westerhof, 2012) and a self-help format with email counseling (Lamers et al., 2015).

A systematic review of web-based interventions showed that often only around $50 \%$ of the participants adhere fully to the program: participants start easily, but also quit easily (Kelders et al., 2012). The second question therefore concerns the adberence to the intervention.

As meta-analyses have shown that both internet interventions (Sander et al., 2016) and life review therapy (Pinquart \& Forstmeier, 2012) can be effective, we assessed how effective their combination in online life review therapy is in diminishing depressive symptoms. We were also interested in the effects of integrative processes (ego-integrity and despair; Lamers et al., 2015), instrumental processes (engaged living and mastery; Cappeliez \& Robitaille, 2010), social processes (social support and loneliness; Korte et al., 2014), as well as in general positive outcomes (vitality and well-being; Westerhof et al., 2010).

The experience of technology-mediated therapy contributes to therapeutic success, just as therapeutic relations are important in face-to-face therapy. Understanding the user experience could therefore further improve online therapy (Feather et al., 2016). Our fourth question was how users experienced the online life review therapy, the contacts with counselor or peers, and the intensity of the intervention.

Last, insights in the interest in and willingness to engage with online interventions are important to keep participants engaged (Berry et al., 2016). We therefore conducted an interview study on the acceptability of the intervention in an interview study. 


\section{Methods}

\section{Design}

The core of our study was a pilot randomized controlled trial (RCT) with three parallel groups (a) Online life review therapy, supported with online counseling (counselor condition), (b) online life review therapy with online peer support (peer condition), and (c) a waitlist control condition (waitlist condition). Participants were randomized based on an automatic, computer-generated list, after they signed informed consent and were included in the study. They received the intervention through internet on their personal computers in their own home and filled out questionnaires online at four measurement points: preintervention (baseline measurement), postmeasurement ( 3 months after baseline), first follow-up (6 months after baseline), and second follow-up (12 months after the baseline). Participants randomized to the waitlist condition could participate in the intervention after 6 months and did not participate in the second follow-up. As part of this study, we assessed baseline characteristics of the participants (reach), changes in primary and secondary outcomes across time (effectiveness), actual use of the intervention (adherence), and participants' postintervention evaluations (user experiences). We assessed interest and willingness to engage (acceptabil$i t y)$ in an interview study at the second follow-up.

\section{Intervention}

The intervention The stories we live by integrates life review with narrative therapy. Bohlmeijer and Westerhof (2013) provide an interpretive case study that describes the dynamics of the therapy. Two earlier studies showed that the intervention is effective in a face-to-face group format (Korte et al., 2012) and as a self-help book with email counseling (Lamers et al., 2015). For the current study, the self-help book was adapted to a completely online context (see Supplementary Materials for a detailed description of the intervention).

There are six modules that can be carried out at home during a period of 12 weeks: younger years and family; adolescence and becoming an adult; work and care; love and friendship; old and new goals; reading your life. The first four modules focus on life themes across the life course from birth to present. In each module, participants were asked questions about the life theme to more easily access relevant autobiographical memories. Next, they were asked to recollect a vivid positive memory as well as to describe a difficult memory. They were guided by narrative therapeutic questions to evaluate and attribute new meanings to the difficult memory. The last two modules focus on the entire life course from the past to the near future in order to integrate memories across different phases of the lifespan.

In the counselor condition, participants carried out their homework and received bi-weekly feedback and support by a trained counselor. The counselors were two Master students in Psychology who received a training to respond from a narrative therapeutic perspective. A licensed health psychologist supervised the students by providing recommendations before the online messages were sent out to the participants.

Participants in the peer condition were randomly assigned to groups of four participants. They carried out the assignments individually and selected which of the weekly assignments they wanted to share with their peers. Participants received instructions about how to provide supportive feedback to other participants. They gave each other feedback every other week. The same two Master students supervised by the licensed health psychologist moderated the conversations and gave recommendations when the participants did not provide supportive feedback.

The waitlist condition did not receive an intervention. Participants were allowed to seek any support they deemed necessary in dealing with their depressive symptoms.

\section{Participants}

Participants were recruited through advertisements in magazines and newsletters for aging adults. Inclusion criteria were an age of 40 years or older and the presence of light to moderate depressive symptoms (Center for Epidemiological Studies-Depression Scale [CES-D] > 10; Beekman et al., 1997). Applicants were excluded when they reported that they started a medication treatment for depressive symptoms within the past 3 months or were currently receiving any other psychological (self-help) treatment for depressive symptoms. Other exclusion criteria were not having enough time to participate in the intervention, having problems with the Dutch language or not having an email address and internet access. Last, presence of severe depressive symptoms and a moderate or high risk of suicidality were exclusion criteria (assessed in a telephone psychiatric interview; Mini International Neuropsychiatric Interview; Sheehan et al., 1998; Van Vliet \& de Beurs, 2007; Sheehan Disability Scale; Leon, Olfson, Portera, Farber, \& Sheehan, 1997).

We expected a moderate effect size (Cohen's $d=.50$ ), based on a meta-analysis (Pinquart \& Forstmeier, 2012) and earlier studies on the intervention (Korte et al., 2012; Lamers et al., 2015). Using a one-sided alpha of .05, a power of .80 , and a dropout of $20 \%, 62$ participants were needed per condition, or 186 in total.

\section{Instruments}

Baseline measurement included demographic characteristics (age, gender, educational level, marital status, living situation, daily activities, internet usage) and health (a visual analogue scale on general health; a 5-point item on subjective health; a 3-point item on health limitations).

The primary outcome of the pilot RCT was depressive symptoms as measured with the CES-D (Beekman et al., 
1997; 20 items, 4-point scale). Secondary outcomes were ego-integrity and despair, engaged living, mastery, social support, loneliness, vitality, and positive mental health. The Northwestern Ego-Integrity Scale (Westerhof, Bohlmeijer, \& McAdams, 2017; 9 items; 6-point scale) measures ego integrity and despair. The Engaged Living Scale (Trompetter et al., 2013; 16 items; 5-point scale) measures an engaged response style. Mastery was measured with the Pearlin Mastery Scale (Pearlin, Lieberman, Menaghan, \& Mullan, 1981; 5 items; 5-point scale). Social support was measured with the short version of the Social Support ListInteractions (SSL-I; Kempen \& van Eijk, 1995; 12 items; 4-point scale). Loneliness was measured with the Dutch loneliness scale (de Jong-Gierveld \& Kamphuis, 1985; 11 items dichotomized 3-point scale). Vitality was measured with a subscale of the MOS SF-36 (Ware \& Sherbourne, 1992; 4 items; 6-point scale). Well-being was measured with the Dutch Mental Health Continuum-Short Form (MHC-SF; Lamers, Westerhof, Bohlmeijer, ten Klooster, \& Keyes, 2011; 14 items; 6-point scale). All scales had adequate to good reliability in our study (Cronbach alpha ranges from .61 for despair to .91 for social support).

The adherence was assessed by automatically recording the actual use of the different functionalities of the application in a logfile for each participant. We used these logfiles to calculate for each participant the number of times logged in, the number of times the help function was consulted, the number of modules finished, the number of visits, the number of downloads of assignments per finished module and the number of communications with the counselor or the peers.

Participants in the counselor and peer condition were asked evaluative questions on the user experience of the intervention: 8 on the intervention, 5 on the online contact with the counselor or peers, and 11 on the intensity of the intervention as well as two open questions on their experience and recommendations (Table 3).

Participants were invited for a telephone interview about the acceptability of the intervention after the second follow-up. All participants were asked questions on their interest for an online intervention (e.g., for which reasons did you choose an online intervention?) and for both conditions (e.g., did you prefer an individual counselor or peer group feedback?). Nonadherent participants were asked for their reasons to quit (e.g., what was the decisive reason to quit the course?), whereas adherent participants were asked questions about their engagement with counselor or peers, depending on which condition they were in.

\section{Analyses}

We used univariate descriptive statistics (percentages, means, and standard deviations) to describe the group of participants we reached. Bivariate statistics (chi-square, $t$-test, analysis of variance [ANOVA]) provide insight in differences between conditions and age groups in baseline characteristics, adherence, and user experience. A binary logistic regression analysis assessed selective dropout of the study. To analyze the effects of the intervention, we carried out a mixed model analysis with correlated residuals for the repeated measure time (baseline, posttreatment, and first follow-up) within the random effect for subject. We specified three fixed factors: condition (waitlist vs counselor vs peer), age group (40-54 years and 55 years and older), and time (baseline, posttreatment, and first followup measurement) as well as their interactions. We tested several covariance types for the repeated factor and compared the model fit (2 log likelihood, Akaike Information Criterion, and Baseysian Information Criterion) to find the best fitting type. For each dependent variable this was the heterogeneous first-order autoregressive type. We used the expected marginal means to compute the difference in Cohen's $d$ between the conditions at follow-up (below .33 is small; between .33 and .55 is moderate; above .55 is large; Lipsey et al., 1993). In each of the two experimental conditions, we used paired $t$-tests comparing the second follow-up (12 months after baseline) with the first followup (6 months after baseline) to assess whether effects were maintained in the long term.

A thematic analysis was carried out to summarize the answers to open questions and interviews. We used the method of constant comparison to develop codes that were driven by the responses the participants gave. New codes were developed when answers did not fit already established codes. We started with a large number of codes that were next grouped into meaningful themes when they had a similar connotation. Each coherent part of an answer that constituted a meaningful unit (mostly a couple of words or a sentence) was coded in terms of a theme. We explain the themes and provide citations to substantiate them in the results section. We did not quantify the results, as we were mainly interested in the content and variation in answers of the participants.

\section{Results}

\section{Question 1: Reach}

Figure 1 presents the participant flow. The age of the 58 participants ranged from 40 to 79 years (mean 53.8; standard deviation $[S D]=8.4)$. Somewhat less than half of them were 55 years or older $(44.8 \%)$. Most were female $(77.6 \%)$ and college educated $(89.8 \%)$. One in three participants were married $(34.5 \%)$, somewhat more than half were living together with a partner and/or children $(55.2 \%)$ and had a paid job $(56.9 \%)$. The average health score was 64.1 on the visual analogue scale from 1 to $100(S D=14.4)$, whereas $60.3 \%$ rated their health as good to excellent and $41.4 \%$ reported no health impairments. Most participants $(63.8 \%)$ used the internet 1 or $2 \mathrm{hr}$ a day and $69.0 \%$ reported that they had (very) much internet experience. There were few differences between the age groups, but middle-aged participants (40-55 years) more often lived together $\left[\chi^{2}(1)=5.3 ; p=.021\right]$ and more often had a job $\left[\chi^{2}(1)=4.1 ; p=.043\right]$. 


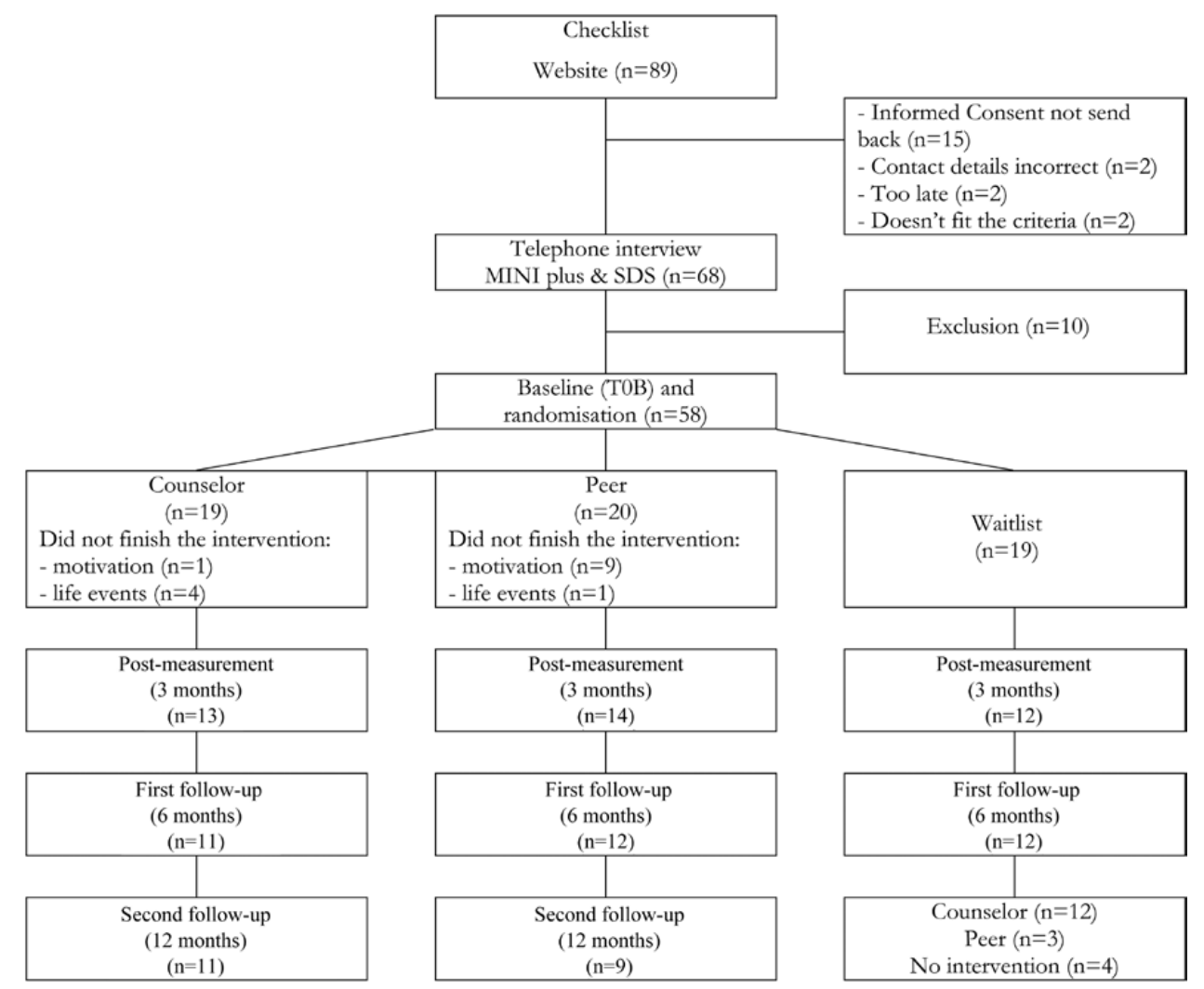

Figure 1. Flow chart of participants.

Participants had higher levels of depressive symptoms and despair and lower levels of ego integrity, engaged living, mastery, and well-being than the general population (Table 1). They had similar levels of functioning as participants in the face-to-face or self-help formats of the intervention, but were somewhat younger, more often female, and higher educated. There were no differences according to age group in these psychosocial variables (all analyses with $p>.05)$. Hence, a vulnerable group was reached among middle-aged, female, and well-educated people in their second half of life.

\section{Question 2: Adherence}

Figure 1 shows the intervention drop-out: 5 participants did not finish the counselor condition versus 10 in the peer condition $\left[\chi^{2}(1)=2.3 ; p=.129\right]$. Drop-outs in the counselor condition mainly experienced important life events, like hospitalization, whereas drop-outs in the peer condition were mainly not motivated $\left[\chi^{2}(1)=7.4 ; p=.007\right]$. Only one group of four participants finished the intervention in the peer condition, three groups had two adherent participants and one group stopped altogether.

Table 2 provides the information on adherence. The use of the application was in general higher in the counselor condition than in the peer condition, although not always significant. Participants in the counselor condition visited the modules significantly more often and downloaded the assignments significantly more often. There were no significant differences between the age groups (all $t$-tests with $p>.05$ ).

\section{Question 3: Effectiveness}

There were no significant differences between the three conditions (counselor, peer, waitlist) in demographical and health characteristics, except that there were more men in the waitlist condition $(42.1 \%)$ than in the counselor $(15.8 \%)$ or the peer condition $\left(10.0 \% ; \chi^{2}(2)=6.5\right.$; $p=.039)$. A multivariate ANOVA showed that the baseline measurements of the primary and secondary outcome measures did not differ significantly across the three conditions $\left(F_{18,96}=1.5 ; p=.095\right)$. Hence, the randomization succeeded, with exception of the gender of the participants.

Figure 1 shows the study drop-out. A stepwise binary logistic regression analysis with participation in the second follow-up as dependent variable and condition, background characteristics as well as baseline measures of primary and secondary variables as independent variables showed no significant predictors for drop-out of the study. Hence, there was no selective study drop-out.

The results of the mixed models for the primary outcome, depressive symptoms, as well as the secondary outcomes can be found in Table 3. For depressive symptoms, there is a significant effect over time, but no significant interaction between condition and time. Across all conditions, depressive symptoms improve between baseline and 
Table 1. Characteristics of the Participants

\begin{tabular}{|c|c|c|c|c|}
\hline Variable & Study & & Mean & $S D$ \\
\hline \multicolumn{5}{|l|}{ Background characteristics } \\
\hline \multirow[t]{3}{*}{ Age } & Current study & & 53.8 & 8.4 \\
\hline & Korte and colleagues (2012) & Face-to-face $(55+\text { years })^{a}$ & 63.3 & 6.5 \\
\hline & Lamers and colleagues (2015) & Self-help $(40+\text { years })^{\mathrm{b}}$ & 56.9 & 9.2 \\
\hline \multirow[t]{3}{*}{ Gender (female) } & Current study & & $77.6 \%$ & \\
\hline & Korte and colleagues (2012) & Face-to-face & $76.7 \%$ & \\
\hline & Lamers and colleagues (2015) & Self-help & $77.0 \%$ & \\
\hline \multirow[t]{3}{*}{ Education (higher) } & Current study & & $89.9 \%$ & \\
\hline & Korte and colleagues (2012) & Face-to-face & $29.7 \%$ & \\
\hline & Lamers and colleagues (2015) & Self-help & $41.3 \%$ & \\
\hline \multirow[t]{4}{*}{ Depressive symptoms } & Current study & & 22.2 & 5.4 \\
\hline & Brailean and colleagues (2016) & Dutch over 55 years & 7.8 & 7.8 \\
\hline & Korte and colleagues (2012) & Face-to-face & 20.6 & 9.4 \\
\hline & Lamers and colleagues (2015) & Self-help & 23.7 & 8.8 \\
\hline \multirow[t]{3}{*}{ Ego integrity } & Current study & & 3.8 & 1.0 \\
\hline & Westerhof and colleagues (2015) & Dutch over 50 years & 4.2 & 0.8 \\
\hline & Lamers and colleagues (2015) & Self-help & 4.1 & 0.8 \\
\hline \multirow[t]{3}{*}{ Despair } & Current study & & 3.9 & 0.9 \\
\hline & Westerhof and colleagues (2015) & Dutch over 50 years & 2.9 & 1.0 \\
\hline & Lamers and colleagues (2015) & Self-help & 4.0 & 0.8 \\
\hline \multirow[t]{3}{*}{ Engaged living } & Current study & & 44.7 & 7.6 \\
\hline & Trompetter and colleagues (2013) & Dutch over 18 years & 60.8 & 7.8 \\
\hline & Trompetter and colleagues (2013) & Pain patients & 50.9 & 9.8 \\
\hline \multirow[t]{3}{*}{ Mastery } & Current study & & 14.8 & 2.6 \\
\hline & Timmer and Aartsen (2003) & Dutch over 55 years & 17.8 & 3.4 \\
\hline & Korte and colleagues (2014) & Face-to-face & 14.8 & 3.4 \\
\hline \multirow[t]{4}{*}{ Well-being } & Current study & & 3.2 & 0.7 \\
\hline & Lamers and colleagues (2011) & Dutch over 18 years & 4.0 & 0.9 \\
\hline & Korte and colleagues (2012) & Face-to-face & 3.4 & 0.8 \\
\hline & Lamers and colleagues (2015) & Self-help & 3.2 & 0.7 \\
\hline
\end{tabular}

"The study of Korte and colleagues (2012) evaluated "The stories we live by" as a face-to-face group intervention for adults older than 55 years.

bThe study of Lamers and colleagues (2015) studied "The stories we live by" as a self-help book with email counseling for adults older than 40 years.

Table 2. Results on Adherence From Log Data

\begin{tabular}{|c|c|c|c|c|c|c|c|c|c|c|}
\hline & \multicolumn{4}{|c|}{ Counselor $(n=19)$} & \multicolumn{4}{|c|}{ Peer $(n=20)$} & \multirow[b]{2}{*}{$t(38)$} & \multirow[b]{2}{*}{ Cohen's $a$} \\
\hline & Mean & $S D$ & Min & Max & Mean & $S D$ & Min & Max & & \\
\hline \multicolumn{11}{|l|}{ General } \\
\hline $\log$ in & 52.0 & 34.1 & 4.0 & 132.0 & 53.3 & 39.4 & 5.0 & 136.0 & -0.1 & -0.03 \\
\hline Help function & 7.8 & 5.9 & 0.0 & 17.0 & 8.6 & 6.9 & 0.0 & 23.0 & -0.4 & -0.12 \\
\hline No. of modules started & 5.1 & 1.6 & 1.0 & 6.0 & 3.9 & 2.4 & 0.0 & 6.0 & 1.9 & 0.59 \\
\hline No. of modules finished & 4.8 & 2.1 & 0.0 & 6.0 & 3.5 & 2.7 & 0.0 & 6.0 & 1.7 & 0.53 \\
\hline No. of visits per module started & 4.3 & 4.1 & 0.0 & 17.2 & 2.3 & 1.8 & 0.0 & 6.0 & $2.0 *$ & 0.65 \\
\hline No. of assignments downloaded per finished module & 3.1 & 2.1 & 0.0 & 10.0 & 1.6 & 2.0 & 0.0 & 9.0 & $2.2 *$ & 1.56 \\
\hline \multicolumn{11}{|l|}{ No. of messages per started module } \\
\hline Sent message to counselor & 0.7 & 0.3 & 0.0 & 1.0 & - & - & - & - & & \\
\hline Opened message from counselor & 1.6 & 1.0 & 0.0 & 4.3 & - & - & - & - & & \\
\hline \multicolumn{11}{|l|}{ No. of messages to group forum per started module } \\
\hline Opened new messages to own posts & - & - & - & - & 1.5 & 1.5 & 0.0 & 4.2 & & \\
\hline Opened messages to group members & - & - & - & - & 3.8 & 3.6 & 0.0 & 11.3 & & \\
\hline Placed message to group members & - & - & - & - & 1.8 & 1.7 & 0.0 & 4.8 & & \\
\hline
\end{tabular}

Note: $t$-tests show no significant differences between the conditions. 


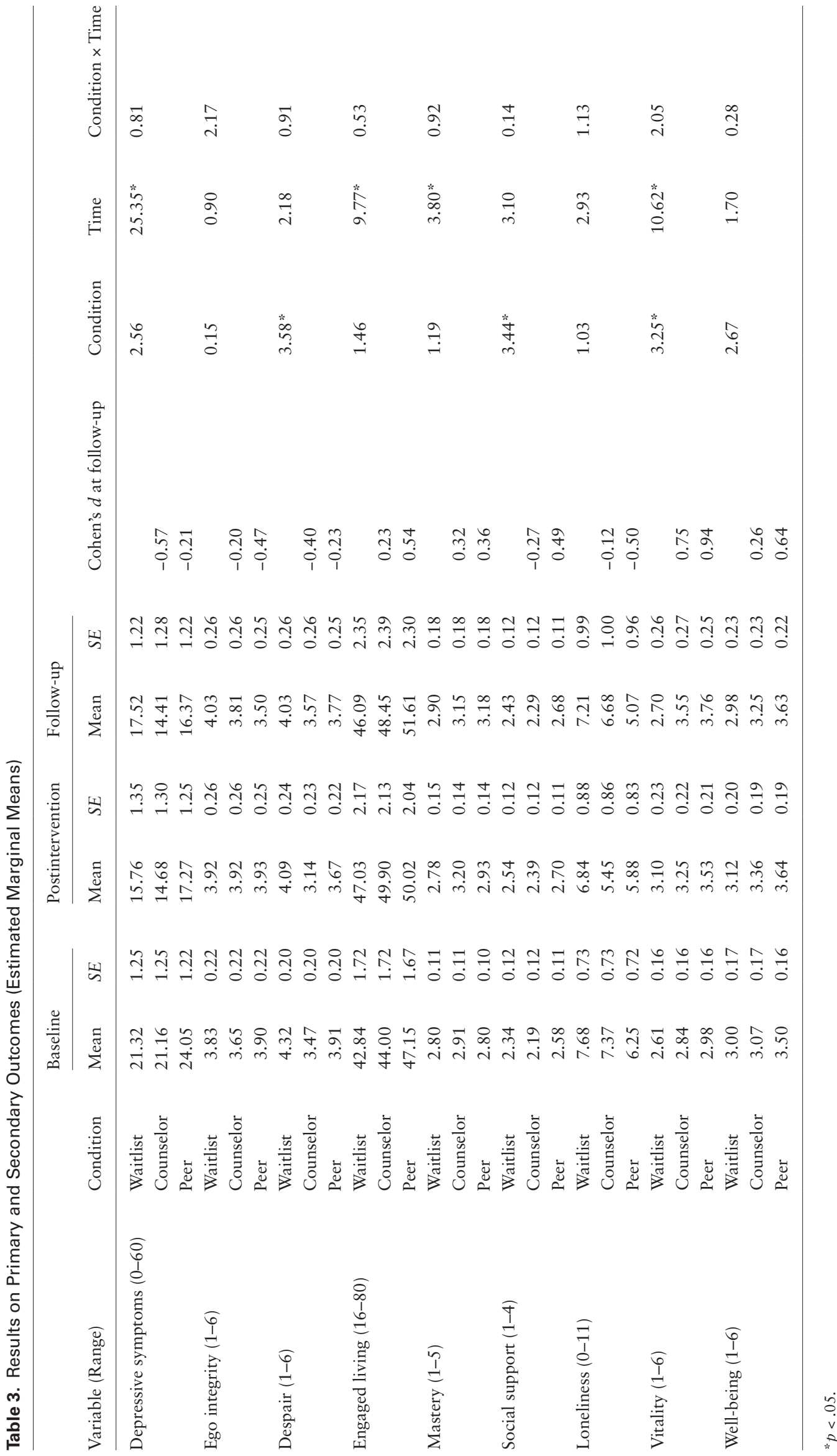


postintervention and remain similar at the first follow-up. There was no significant interaction with age group (40-54 years and 55 years and older). At follow-up there is a moderate difference (Cohen's d) between the counselor and the waitlist condition and a small difference between the peer and the waitlist condition. For those who also participated in the second follow-up, 1 year after the start of the intervention, paired $t$-tests showed that there is a significant difference between the second and the first follow-up in the counselor condition $(t(9)=-3.6 ; p=.006)$, but not in the peer condition $(t(8)=0.7 ; p=.517)$, suggesting that effects were better maintained in the peer condition in the longer term.

There were no significant interactions between condition, age group, and time for all secondary outcomes. In all conditions, there was a significant improvement of engaged living, mastery, and vitality across time. At follow-up there were small to moderate differences (Cohen's $d$ ) in engaged living and mastery as well as large differences in vitality between the intervention conditions and the waitlist condition. The paired $t$-tests showed that despair declined in the counselor condition at the second follow-up, 1 year after the baseline $(t(9)=-2.3 ; p=.048)$. They also showed that there is an improvement in well-being in the peer condition at the longer term $(t(8)=2.8 ; p=.022)$. No further $t$-tests were significant.

\section{Question 4: User Experience}

At post-test, participants in the counselor and peer condition evaluated the intervention. Overall, the quantitative analyses showed that the evaluations were positive (above the midpoint of the respective scales; Table 4). The counselor condition was in general more positively evaluated than the peer condition, but there were only significant differences in terms of general satisfaction about the intervention and recommendation of the intervention to acquaintances. Participants also spent significantly more time in the counselor than the peer condition. There were no differences between the age groups (all $t$-tests with $p>.05$ ).

In response to an open evaluative question, participants mentioned three positive and one negative theme: the intervention, the writing process, the things they learned, and disappointment. Positive remarks about the intervention were, for example, "it gave me structure" or "it confronted me with personal life experiences." The writing process was also mentioned: "by reflecting and writing, I became more aware of my life." Gains were for example "it gave

Table 4. Results on Process Evaluation

\begin{tabular}{|c|c|c|c|c|c|c|c|}
\hline & \multirow[b]{2}{*}{ Range } & \multicolumn{2}{|c|}{ Counselor } & \multicolumn{2}{|c|}{ Peer } & \multirow[b]{2}{*}{$t(29)$} & \multirow[b]{2}{*}{ Cohen's $d$} \\
\hline & & $(N=$ & & $(N=$ & & & \\
\hline \multicolumn{8}{|l|}{ Evaluation of the online intervention } \\
\hline Intervention general & $1-10$ & 7.4 & 1.1 & 6.7 & 1.4 & 1.6 & 0.59 \\
\hline Satisfied in general & $1-4$ & 3.1 & 0.5 & 2.8 & 0.7 & 1.5 & 0.55 \\
\hline Quality of the intervention & $1-4$ & 2.9 & 0.8 & 2.7 & 0.8 & 0.7 & 0.24 \\
\hline Satisfy your needs & $1-4$ & 2.8 & 0.7 & 2.3 & 0.6 & $2.3 *$ & 0.84 \\
\hline Kind of help you hoped for & $1-4$ & 2.7 & 0.8 & 2.5 & 0.8 & 0.4 & 0.16 \\
\hline Help cope with complaints & $1-4$ & 2.9 & 0.6 & 2.5 & 0.8 & 1.5 & 0.54 \\
\hline Recommend to acquaintances & $1-4$ & 3.2 & 0.8 & 2.4 & 0.7 & $2.9^{*}$ & 1.06 \\
\hline Start over again & $1-4$ & 2.8 & 0.9 & 2.2 & 0.9 & 1.8 & 0.66 \\
\hline \multicolumn{8}{|l|}{ Evaluation of contacts } \\
\hline Contact general & $1-10$ & 7.7 & 2.0 & 6.2 & 2.5 & 1.8 & 0.64 \\
\hline Computer contact: pleasant & $1-4$ & 3.5 & 1.0 & 3.1 & 1.1 & 1.1 & 0.39 \\
\hline Computer contact: personal & $1-4$ & 3.0 & 0.9 & 2.7 & 1.2 & 0.9 & 0.32 \\
\hline Computer contact: meaningful & $1-4$ & 3.4 & 1.1 & 3.3 & 1.0 & 0.4 & 0.13 \\
\hline Missed other forms of contact & $1-3$ & 1.9 & 0.9 & 2.1 & 0.8 & -0.4 & -0.16 \\
\hline \multicolumn{8}{|l|}{ Evaluation of the intensity } \\
\hline Hours spent per week & $0-10$ & 4.2 & 2.5 & 2.3 & 1.2 & $2.6^{*}$ & 0.96 \\
\hline Amount of help received & $1-4$ & 3.1 & 0.6 & 2.7 & 0.6 & 1.8 & 0.65 \\
\hline Number of modules (6)? & $1-5$ & 2.6 & 0.5 & 2.6 & 0.7 & 0.0 & 0.00 \\
\hline Number of weeks (12)? & $1-5$ & 2.5 & 0.5 & 2.8 & 0.8 & -1.1 & -0.41 \\
\hline Number of assignments & $1-5$ & 3.1 & 0.5 & 3.1 & 0.5 & 0.0 & 0.00 \\
\hline Quantity of text & $1-5$ & 3.2 & 0.6 & 3.3 & 0.5 & -0.4 & -0.13 \\
\hline Number of examples & $1-5$ & 3.3 & 0.9 & 3.2 & 0.7 & 0.2 & 0.08 \\
\hline Quantity of contact & $1-5$ & 2.6 & 0.6 & 2.3 & 0.8 & 1.3 & 0.46 \\
\hline Number of peers & $1-5$ & - & - & 2.8 & 0.9 & & \\
\hline
\end{tabular}

$* p<.05$. 
me insight," "I discovered a thread in my life," "I started to think more positively" or "it brought more balance in my life."

A few participants were disappointed, for example, "It did not contribute much to the insights I already had before the intervention."

In response to an open question about improvements of the intervention, participants mentioned three themes: contact, technology, and time investment. With regard to contact, participants would like to have more (profound) contact with the counselor or peers: "I missed Personal contact"; "I found the counselor more facilitating than counseling." Some mentioned technical problems: "I had difficulty saving my work on the tablet." With regard to time investment, some would have preferred more time per module ("some more time for the lessons"), whereas others thought the modules did not advance quick enough: "the time frame in which the six lessons are offered is far too long."

\section{Question 5: Acceptability}

Interviews were held with 15 participants in the counselor condition and 17 in the peer condition. Other participants could no longer be reached or were not motivated to participate. Five themes were found in the interview study regarding the acceptability of the intervention: the online format, the preference for a counselor-led or peersupported format, reasons for discontinuing the intervention, the counselor relationship, and the peer relationships.

In the interview study, most participants stated that they preferred an online format, because they could follow the course in their own time and their own home: "you can follow the course in your own time through internet." Some also preferred the anonymity of the online intervention: "your relative anonymity makes it easier to talk about certain things." Others mentioned the communication as a negative aspect: they stated to regret that they could only communicate in writing and with a delay in time, for example, "when you give an answer and want to go deeper, that is not possible at that moment, that is a pity." Some participants also reported technical problems, for example, "whole parts of the text disappeared." However, most of them were satisfied with the technical support that "quickly resolved their problems."

Most participants had a preference for an individual trajectory with a counselor, whereas some had no clear preference and only a few had a preference for the peer group. Participants with a preference for the counselor did not want to share their stories with other participants ("I would rather share my experience with a single person and not a whole group"). A person with no preference mentioned that "most important for me was to receive feedback from someone, and it didn't matter to me whether that was a peer or a counselor." Participants who preferred the peer condition would like to share their stories and learn from other people: "because you hear stories of others and learn from them."

Participants gave several reasons for discontinuing the intervention. In both conditions participants mentioned personal circumstances as reason (e.g., "a lot of work to do", "summer holidays") and others that it was hard to be confronted with their past or their complaints ("my complaints worsened as a result of the confrontation with the past, so it was too early for me to do this course"). The peer aspect was a reason for some participants to quit the peer condition: they did not feel comfortable reading the stories of their peers, they did not recognize themselves in stories of persons of different age groups, or they did not get response from others. For example, "I hear stories from peers that are more difficult and touching than my own."

Participants were more positive than negative about the counseling relationship. Participants mentioned that the guidance was substantive with "stimulating questions," "new insights," and "valuable advice." Counselors were seen as friendly, positive, and personal. Others mentioned that the counseling was "impersonal": "I had the impression that the answers came from a book". A few also said that the time between the online messages was "too long" or that there was no possibility "to really engage in a conversation."

Participants were somewhat more negative than positive about the peer relations. The most important theme was that they didn't feel connected to their peers. They did not like to share their stories with people they never met or felt obliged to respond: "you have to be kind of a counselor." Some did not like to read about the problems of peers who experienced rather different problems than their own: "I did not need to hear all the problems of other people." Others explained that their peers were not open, did not respond empathically or did not react or even had quit the intervention: "sometimes I thought: you really don't get it." By contrast, participants also mentioned that there was an engaged and intensive contact with other group members who are at the same level: "It was really nice to discuss with someone." Some were "empathic" to their peers and could give them "good advice," whereas they also felt "supported" by their peers. Others were open to share their stories with people they didn't know and liked the openness of their peers as well: "So much was exposed in depth."

\section{Discussion}

Life review therapy is an effective intervention to treat depressive symptoms in later life (Bohlmeijer et al., 2003; Pinquart \& Forstmeier, 2012; Scogin et al., 2005). Given the increasing use of digital technologies, also in older age groups, an online life review therapy appears to be a timely innovation. In this study, we compared a format that was led online by a counselor to an online format with peer support in middle-aged and older persons. The intervention reached a vulnerable group of mainly somewhat younger, college educated women. The adherence was stronger in 
the counselor condition than in the peer condition. The pilot RCT on effectiveness showed that all participants improved significantly in depressive symptoms, engaged living, mastery, and vitality, but not in ego integrity and despair, social support, loneliness, and well-being. The user experience and acceptability were in general positive, but somewhat more so for the counselor than the peer condition. Except that more middle-aged persons were reached, there were no differences between the age groups in adherence, effectiveness, and user experience.

This is the first study to evaluate a completely online life review therapy for depressive symptoms. Unlike meta-analyses on online interventions (Sander et al., 2016) and on life review therapy (Pinquart \& Forstmeier, 2012), online life review therapy did not result in a stronger decrease in depressive symptoms as compared to the waiting list control group. First, depressive symptoms also declined in the waiting list control group. This was also found in a study on life review as self-help with email guidance (Lamers et al., 2015), but not in a study on life review as face-to-face group intervention (Korte et al., 2012). Although the baseline levels of depressive symptoms are not much different between these studies, digital formats might have a lower threshold for people to start, so there might be some more spontaneous recovery in this group. Second, the life review might have been somewhat less profound as no changes were found in ego integrity or despair. Last, as a result of the recruitment problems and the nonadherence, we have to be careful in drawing conclusions about the effectiveness. A lack of statistical power might account for the lack of significant effects, as the moderate effect size between the counselor and waitlist condition in depressive symptoms at follow-up is in the expected range (Korte et al., 2012; Lamers et al., 2015; Pinquart \& Forstmeier, 2012).

Participants were in general satisfied with the online delivery of the intervention. They mentioned reasons to participate in an online intervention that were also found in other studies (Beattie et al., 2009; Cuijpers et al., 2010): the perceived anonymity and the flexibility to carry out assignments in their own time and place. Although participants were in general positive about the contacts in the intervention, some would have preferred more profound personal contact. A good blending between online and face-to-face contact might be a solution, for example, doing assignments via online modules, but discussing thoughts and feelings face-to-face (Van der Vaart et al., 2014). The recollection of memories might be easier stimulated online, whereas evaluating and integrating memories might demand more face-to-face counseling.

We compared a counselor-led and a peer-supported form of life review therapy. Although there were no differences in effectiveness, the counselor condition resulted in better adherence, user experiences, and acceptability than the peer condition. Almost half of the participants in the peer condition did not adhere to the intervention, which is not uncommon in online interventions (Kelders et al., 2012). From the interviews it became clear that most participants would have preferred individual counseling and that some had difficulty establishing contact with their peers. Given the large age range of participants, the different life circumstances of middle-aged and older adults might have contributed to the difficulties in establishing contacts. This might also be related to the random assignment to peer groups. Hence, the intervention did not have the advantages of a group intervention for all participants (Korte et al., 2014). As some participants evaluated the peer support positively, it would be worthwhile to study the effects when participants select the peer support mode and their peers themselves, for example, based on a short introductory statement by each participant. A better mix between counselor and peer feedback might be helpful: the counselor could provide more in-depth feedback directed at the integrative functions of reminiscence, whereas peers could support the social functions of reminiscence (Korte et al., 2014).

We evaluated the online intervention in middle-aged and older adults. As in other studies, the intervention mainly attracted higher educated middle-aged women (Kelders et al., 2013). Nevertheless, the middle-aged and older groups were both vulnerable in terms of depressive symptoms and psychosocial functioning. Both age groups also did not differ in terms of adherence, effectiveness, or user experience. On the one hand, life review therapy might indeed match continuities in thinking back and reflecting on life throughout the lifespan (Fivush et al., 2011; Westerhof \& Bohlmeijer, 2014). On the other hand, the older adults who participate in the online intervention might be the early adopters of their generation. The increasing use of digital technologies will quickly expand the possible user groups in midlife and beyond.

It proved hard to include the required number of persons, despite an extension of the recruitment period and extra means for advertising. This compromised the statistical power of the study. Furthermore, we focused on individual participants as this was a first experimental study on online life review therapy. Further research should also include stakeholders like counselors, mental health institutes, and health insurance companies, to assess the adoption, implementation, and maintenance of online life review therapy in everyday mental health practice (Kessler et al., 2013). Such research might also shed further light on the question which blend between face-to-face and online contact and between counselor and peer support works best to support which functions of reminiscence and life review in individuals of different ages.

\section{Supplementary Material}

Supplementary data are available at The Gerontologist online.

\section{Funding}

The study was funded by the University of Twente, the Netherlands. 


\section{Acknowledgements}

The Medical Ethical Review Board Twente approved this study (number NL 41224.044.12). It is registered in the Netherlands Trial Register (number NTR3536). We would like to thank Sharda Bachoe and Helene van Tol for their work as counselors and Mareike Backhaus, Lotte van der Lelij, and Maaike Blok for their work on the qualitative parts of this manuscript.

\section{Conflict of Interest}

None declared.

\section{References}

Beattie, A., Shaw, A., Kaur, S., \& Kessler, D. (2009). Primarycare patients' expectations and experiences of online cognitive behavioural therapy for depression: A qualitative study. Health Expectations, 12, 45-59. doi:10.1111/ j.1369-7625.2008.00531.x

Beekman, A. F., Deeg, D. H., Van Limbeek, J., Braam, A. W., De Vries, M. Z., \& Van Tilburg, W. (1997). Criterion validity of the Center for Epidemiologic Studies Depression scale (CESD): Results from a community-based sample of older subjects in the Netherlands. Psychological Medicine, 27, 231-235. doi:10.1017/S0033291796003510

Berry, N., Lobban, F., Emsley, R., \& Bucci, S. (2016). Acceptability of interventions delivered online and through mobile phones for people who experience severe mental health problems: A systematic review. Journal of Medical Internet Research, 18, e121. doi:10.2196/jmir.5250

Birren, J. E., \& Deutchman, D. E. (1991). Guided autobiography groups for older adults. Baltimore, MD: John Hopkins University Press.

Bohlmeijer, E. T., Smit, F., \& Cuijpers, P. (2003). Effects of reminiscence and life review on late-life depression: A meta-analysis. International Journal of Geriatric Psychiatry, 18, 1088-1094. doi:10.1002/gps.1018

Bohlmeijer, E. T., \& Westerhof, G. J. (2013). Life review as a way to enhance personal growth in midlife: A case-study. International Journal of Reminiscence and Life Review, 1, 13-18.

Brailean, A., Comijs, H. C., Aartsen, M. J., Prince, M., Prina, A. M., Beekman, A., \& Huisman, M. (2016). Late-life depression symptom dimensions and cognitive functioning in the Longitudinal Aging Study Amsterdam (LASA). Journal of Affective Disorders, 201, 171-178. doi:10.1016/j.jad.2016.05.027

Buntrock, C., Berking, M., Smit, F., Lehr, D., Nobis, S., Riper, H.,...Ebert, D. (2017). Preventing depression in adults with subthreshold depression: Health-economic evaluation alongside a pragmatic randomized controlled trial of a web-based intervention. Journal of Medical Internet Research, 19, e5. doi:10.2196/ jmir.6587

Cappeliez, P., \& Robitaille, A. (2010). Coping mediates the relationships between reminiscence and psychological well-being among older adults. Aging \& Mental Health, 14, 807-818. doi:10.1080/13607861003713307

CBS. (2015). ICT use by personal characteristics [in Dutch]. Retrieved June 30, 2015 from http://statline.cbs.nl/
Cuijpers, P., van Straten, A., Warmerdam, L., \& van Rooy, M. J. (2010). Recruiting participants for interventions to prevent the onset of depressive disorders: possible ways to increase participation rates. BMC Health Services Research, 10, 181. doi:10.1186/1472-6963-10-181

de Jong-Gierveld, J., \& Kamphuis, F. (1985). The development of a Rasch-type loneliness scale. Applied Psychological Measurement, 9, 289-299. doi:10.1177/014662168500900307

Feather, J. S., Howson, M., Ritchie, L., Carter, P. D., Parry, D. T., \& Koziol-McLain, J. (2016). Evaluation methods for assessing users' psychological experiences of web-based psychosocial interventions: A systematic review. Journal of Medical Internet Research, 18, e181. doi:10.2196/jmir.5455

Fivush, R., Habermas, T., Waters, T. E., \& Zaman, W. (2011). The making of autobiographical memory: Intersections of culture, narratives and identity. International Journal of Psychology: Journal international de psychologie, 46, 321-345. doi:10.108 0/00207594.2011.596541

Griffiths, K. M., Farrer, L., \& Christensen, H. (2010). The efficacy of internet interventions for depression and anxiety disorders: A review of randomised controlled trials. The Medical Journal of Australia, 192(11 Suppl.), S4-S11.

Griffiths, K. M., Mackinnon, A. J., Crisp, D. A., Christensen, H., Bennett, K., \& Farrer, L. (2012). The effectiveness of an online support group for members of the community with depression: A randomised controlled trial. PLoS ONE, 7, e53244. doi:10.1371/journal.pone.0053244

Haight, B. K., Coleman, P., \& Lord, K. (1995). The linchpins of a successful life review: Structure, evaluation and individuality. In B.K. Haight \& J.D. Webster (Eds.), The art and science of reminiscing (pp. 179-192). Washington, DC: Taylor \& Francis.

Hallford, D. J., \& Mellor, D. (2016). Autobiographical memorybased intervention for depressive symptoms in young adults: A randomized controlled trial of cognitive-reminiscence therapy. Psychotherapy and Psychosomatics, 85, 246-249. doi:10.1159/000444417

Kelders, S. M., Bohlmeijer, E. T., \& Van Gemert-Pijnen, J. E. (2013). Participants, usage, and use patterns of a web-based intervention for the prevention of depression within a randomized controlled trial. Journal of Medical Internet Research, 15, e172. doi:10.2196/jmir.2258

Kelders, S. M., Kok, R. N., Ossebaard, H. C., \& Van Gemert-Pijnen, J. E. (2012). Persuasive system design does matter: A systematic review of adherence to web-based interventions. Journal of Medical Internet Research, 14, e152. doi:10.2196/jmir.2104

Kempen, G. M. \& Van Eijk, L. M. (1995). The psychometric properties of the SSL12-I, a short scale for measuring social support in the elderly. Social Indicators Research, 35, 303-312. doi:10.1007/BF01079163

Kessler, R. S., Purcell, E. P., Glasgow, R. E., Klesges, L. M., Benkeser, R. M., \& Peek, C. J. (2013). What does it mean to "employ" the RE-AIM model? Evaluation of the Health Professions, 36, 44-66. doi:10.1177/0163278712446066

Kohl, L. F., Crutzen, R., \& de Vries, N. K. (2013). Online prevention aimed at lifestyle behaviors: A systematic review of reviews. Journal of Medical Internet Research, 15, e146. doi:10.2196/jmir.2665

Korte, J., Bohlmeijer, E. T., Cappeliez, P., Smit, F., \& Westerhof, G. J. (2012). Life review therapy for older adults with moderate 
depressive symptomatology: A pragmatic randomized controlled trial. Psychological Medicine, 42, 1163-1173. doi:10.1017/ S0033291711002042

Korte, J., Drossaert, C. H., Westerhof, G. J., \& Bohlmeijer, E. T. (2014). Life review in groups? An explorative analysis of social processes that facilitate or hinder the effectiveness of life review. Aging \& Mental Health, 18, 376-384. doi:10.1080/13607863. 2013.837140

Lamers, S. M., Bohlmeijer, E. T., Korte, J., \& Westerhof, G. J. (2015). The efficacy of life-review as online-guided self-help for adults: A randomized trial. The Journal of Gerontology: Psychological Sciences and Social Sciences, 70, 24-34. doi:10.1093/geronb/gbu030

Lamers, S. M., Westerhof, G. J., Bohlmeijer, E. T., ten Klooster, P. M., $\&$ Keyes, C. L. (2011). Evaluating the psychometric properties of the Mental Health Continuum-Short Form (MHC-SF). Journal of Clinical Psychology, 67, 99-110. doi:10.1002/jclp.20741

Lazar, A., Thompson, H., \& Demiris, G. (2014). A systematic review of the use of technology for reminiscence therapy. Health Education \&o Behavior, 41 (1 Suppl.), 51S-61S. doi:10.1177/1090198114537067

Leon, A. C., Olfson, M., Portera, L., Farber, L., \& Sheehan, D. V. (1997). Assessing psychiatric impairment in primary care with the Sheehan Disability Scale. International Journal of Psychiatry in Medicine, 27, 93-105. doi:10.2190/ T8EM-C8YH-373N-1UWD

Lipsey, M. W. \& Wilson, D. B. (1993). The efficacy of psychological, educational, and behavioral treatment. Confirmation from meta-analysis. The American Psychologist, 48, 1181-1209. doi:10.1037/0003-066X.48.12.1181

Melling, B. \& Houguet-Pincham, T. (2011). Online peer support for individuals with depression: A summary of current research and future considerations. Psychiatric Rehabilitation Journal, 34, 252-254. doi:10.2975/34.3.2011.252.254

Pearlin, L. I., Lieberman, M. A., Menaghan, E. G., \& Mullan, J. T. (1981). The stress process. Journal of Health and Social Behavior, 22, 337-356. doi:10.2307/2136676

Pinquart, M. \& Forstmeier, S. (2012). Effects of reminiscence interventions on psychosocial outcomes: A meta-analysis. Aging \& Mental Health, 16, 541-558. doi:10.1080/13607863.2011.651 434

Sander, L., Rausch, L., \& Baumeister, H. (2016). Effectiveness of internet-based interventions for the prevention of mental disorders: A systematic review and meta-analysis. JMIR Mental Health, 3, e38. doi:10.2196/mental.6061

Scogin, F., Welsh, D., Hanson, A., Stump, J., \& Coates, A. (2005). Evidence-based psychotherapies for depression in older adults. Clinical Psychology: Science and Practice, 12, 222-237. doi:10.1093/clipsy/bpi033
Sheehan, D.V., Lecrubier, Y., Sheehan, K.H., Amorim, P., Janavs, J., Weiller, E.,...Dunbar, G. C. (1998). The Mini-International Neuropsychiatric Interview (M.I.N.I). Journal of Clinical Psychiatry, 59, 22-33.

Thomas, L. \& Briggs, P. (2016). Reminiscence through the lens of social media. Frontiers in Psychology, 7, 870. doi:10.3389/ fpsyg.2016.00870

Timmer, E. \& Aartsen, M. (2003). Mastery beliefs and productive leisure activities in the third age. Social Behavior and Personality, 31, 643-656. doi:10.2224/sbp.2003.31.7.643

Trompetter, H. R., Ten Klooster, P. M., Schreurs, K. M., Fledderus, M., Westerhof, G. J., \& Bohlmeijer, E. T. (2013). Measuring values and committed action with the Engaged Living Scale (ELS): Psychometric evaluation in a nonclinical sample and a chronic pain sample. Psychological Assessment, 25, 1235-1246. doi:10.1037/a0033813

van der Vaart, R., Witting, M., Riper, H., Kooistra, L., Bohlmeijer, E. T., \& van Gemert-Pijnen, L. J. (2014). Blending online therapy into regular face-to-face therapy for depression: Content, ratio and preconditions according to patients and therapists using a Delphi study. BMC Psychiatry, 14, 355. doi:10.1186/s12888-014-0355-z

Van Deurzen, A. J. A. M., \& Van Dijk, J. A. G. M. (2015). Internet skills increase but gaps widen. Information, Communication, \& Society, 18, 782-797. doi:10.1080/1369118X.2014.994544

Van Gemert-Pijnen, L., Peters, O., \& Ossebaard, H. (2013). Improving eHealth. Den Haag: Eleven.

van Vliet, I. M. \& de Beurs, E. (2007). [The MINI-International Neuropsychiatric Interview. A brief structured diagnostic psychiatric interview for DSM-IV en ICD-10 psychiatric disorders]. Tijdschrift voor Psychiatrie, 49, 393-397.

Ware, J. E., Jr. \& Sherbourne, C. D. (1992). The MOS 36-item short-form health survey (SF-36). I. Conceptual framework and item selection. Medical Care, 30, 473-483. doi:10.1097 /2F00005650-199206000-00002

Westerhof, G. J. (2017). Technologies to remember or forget? International Journal of Reminiscence and Life Review, 4, 8-13.

Westerhof, G. J. \& Bohlmeijer, E. T. (2014). Celebrating fifty years of research and applications in reminiscence and life review: State of the art and new directions. Journal of Aging Studies, 29, 107-114. doi:10.1016/j.jaging.2014.02.003

Westerhof, G. J., Bohlmeijer, E. T., \& McAdams, D. P. (2017). The relation of ego integrity and despair to personality traits and mental health. The Journal of Gerontology: Psychological Sciences and Social Sciences, 72, 400-407. doi:10.1093/geronb/gbv062

Westerhof, G. J., Bohlmeijer, E. T., \& Webster, J. D. (2010). Reminiscence and mental health: A review of recent progress in theory, research and interventions. Ageing \& Society, 30, 697721. doi:10.1017/S0144686X09990328 